\title{
İstanbul ve Eskişehir Bölgesi Minimum-Maksimum Yağış Miktarlarının Ekstrem Değerler Dağılımları Ailesi ile Modellenmesi
}

\author{
Mustafa ÇAVUŞ ${ }^{* 1}$, Özer ÖZDEMİR ${ }^{2}$, Ahmet SEZER ${ }^{3}$ \\ 1,2,3Eskişehir Teknik Üniversitesi, Fen Fakültesi, İstatistik Bölümü, 26555, Eskişehir, Türkiye \\ ${ }_{1}^{1}$ (ORCID: https://orcid.org/0000-0002-6172-5449) \\ 2 (ORCID: https://orcid.org/0000-0003-2446-5139) \\ 3(ORCID: https://orcid.org/0000-0002-5962-4999)
}

(Alınış / Received: 10.04.2018, Kabul / Accepted: 18.12.2018, Online Yayınlanma / Published Online: 06.03.2018)

Anahtar Kelimeler

Ekstrem değerler teorisi, Parametre tahmini, Blok maksimum yöntemi, Fitdistrplus
Özet: Ekstrem (uç) olaylar doğada az olasılıkla ortaya çıkmakla birlikte, ortaya çıktklarında etki alanları hem ekonomik hem de çevresel olarak büyük olmaktadır. Bu yüzden bu tür olayların hangi olasılıkla ortaya çıkabileceği, bu konuda alınması gereken tedbirlerin neler olması gerektiği konusunda belirleyici olmaktadır. Ekstrem(uç) değerler dağılımları ailesindeki dağılımların parametrelerinin doğru belirlenmesi ekstrem olasılıkların doğru hesaplanmasına katkıda bulunacaktır. Literatürdeki Weibull, Frechet, Gumbell dağllımlarına ilişkin parametreler R programında yer alan fitdistrplus fonksiyonu kullanılarak elde edilecektir. Bu çalışmada ülkemiz nüfusunun yoğun olarak bulunduğu İstanbul bölgesi ve Eskişehir bölgesindeki maksimum ve minimum yağış miktarlarının dağılımı blok maksimum yöntemi kullanılarak araştırılacaktır. Bu dağlımlardan elde edilecek sonuçlar, potansiyel risklere ve firsatlara karar verilmesine yardımcı olacaktır.

\section{Modelling of Maximum and Minimum Rainfall of Istanbul and Eskisehir Region by the Family of Extreme Value Distributions}

\section{Keywords}

Extreme value theory, Parameter estimation, Block maxima, Fitdistrplus

\begin{abstract}
Extreme events are rarely occurred but once they appear they may end up with serious consequences as both economic and environmental areas. There is no question that it is important to predetermine consequences of this kind of events. To determine possible consequences, we should accurately decide the parameters of the family of extreme value distributions. The parameters of Weibull, Frechet and Gumbell distributions in the literature will be obtained by using fitdistrplus package in R. In this study, the distribution of maximum and minimum precipitation of Istanbul which has high population rate in our country and Eskisehir region will be investigated by using block maximuma. The results which will be obtained from these distributions will help us to determine the potential risks and opportunities.
\end{abstract}

\section{Giriş}

Uç (Ekstrem) olaylar çoğunlukla beklenmeyen, olağandışı, nadir olarak gözlemlenebilen olaylardır. Ancak birçoğu önemli sonuçlar doğurabilecek niteliktedir. Uç olayların ortaya çıkabilme ihtimalinin hesabı birçok disiplin için oldukça önemlidir. Uç olaylar sonucu ortaya çlkan uç değerler ise, bir veri seti içerisindeki en büyük ya da en küçük değerlerdir.

Uç olayların ihtimallerini hesaplamak, birçok bilim dalı için çok önemlidir. Uç değerler teorisi ilk olarak Frechet [1] tarafindan 1927 yılında oluşturulmaya başlanmış ve bir yl sonra Fisher ve Tippet [2] tarafından 1928 yılında yayımlanan makale ile geliştirilmiştir. Gnedenko [3] tarafından 1943 yılında yapılan çalışmalara ek olarak, E. J. Gumbel [4] teoriyi pekiștirmiștir.

Uç değerler teorisi birçok alanda kendine uygulama bulmuş olan bir teoridir. Başlıca uygulama alanları hidroloji [5, 7], finans [8, 9], telekomünikasyon ve uç olaylarla ilgili tüm alanlardır. Uç değerler teorisi ve uygulama alanları ile ilgili yapılan çalışmalar şu şekilde özetlenebilir.

1928 yılındaki çalışmasında Fisher-Tippet, uç değerler teorisinde üç tür limit dağılımı olduğunu [2], Weibull [10] ve Gumbel [11] ise uç değerler teorisinin uygun dağılımlara bağlı olarak modellenebileceğini göstermiştir. 
Stephens [12] hazırladığı teknik raporda ekstrem(uç) değer dağılımının uygunluk testlerini incelemiştir. Öncelikle en çok olabilirlik yöntemi ile parametre tahmini göstermiş, sonrasında ise tahmin edilen parametreler üzerinden çeşitli uygunluk sınamalarını denemiştir. Sukhatme [13], Durbin [14] ve Stephens [15] testleri ele alınarak bir Monte Carlo simülasyon çalışması yapılmıştır. Çalışma sonucunda Stephens testinin limit dağılımının daha hızlı yakınsama sonuçları verdiği görülmüştür.

Gençay ve Selçuk [16] gelişmekte olan 9 farklı piyasaya ait günlük borsa getirilerini incelemiş, varyans-kovaryans ve benzetim yöntemlerinden faydalanarak uç değerler teorisi ile VaR tahminlerini elde etmişlerdir.

Gilli ve Kellezi [17] kuyruk riski ölçümlerinin ve ilgili güven aralıklarının hesaplanmasında birçok borsa verisi üzerinde inceleme yapmışlardır.

Goncu vd. [18] IMKB verilerini UDK yardımıyla modellemiş ve modellemede Gumbel, Frechet ve Weibull dağılımlarından yararlanılarak VaR hesaplamış ve geriye dönük test sonuçlarını incelemişlerdir.

Ferreira ve Hann [19] çalışmasında Blok maksimum yöntemi üzerinde, eşik değer yöntemine göre daha az çalışma yapıldığı vurgusu yapılmıştır. Bu yüzden çalışmalarında bu iki ekstrem değer belirleme yönteminin teorik bir karşılaştırmasını yapmıştır. Bu karşılaştırmayı yapabilmek için ise tahmin yöntemi olarak 1985 yllında Hosking, Walls ve Wood tarafından ortaya atılan Olasılıksal Ağırlıklandırılmış Moment tahminini kullanmıștır [20]. Çalıșmanın sonucunda Blok maksimum yönteminin Eşik değer yöntemine göre daha etkin bir yöntem olduğunu gözlemlemiştir. Miroslava [6] Belgrad şehrindeki yıllık maksimum yağış miktarlarını modellediği çalışmasında mevsimsel özellik gösteren verilerde blok maksimum yönteminin eşiği aşan değerler yöntemine göre ekstrem değerleri belirlemede daha etkin sonuçlar verdiğini göstermiștir. Bu nedenle çalışmada Blok Maksimum (BM) yöntemi kullanılmıştır.

Bu çalışmada amaç doğada az olasılıkla ortaya çıkan ancak etki alanları hem ekonomik hem de çevresel olarak büyük olan, ülkemiz nüfusunun yoğun olarak yaşadığı İstanbul bölgesi ve Havacılık etkinliklerinin yoğun olduğu Eskişehir bölgesindeki ekstrem yağış miktarlarının BM yöntemi kullanılarak Ekstrem Değerler Ailesi dağılımları ile modellenmesidir. Özellikle Eskişehir bölgesi için böyle bir araştırma yapılmamış olması ve diğer çalışmalardan farklı olarak maksimum yağış miktarlarının yanı sıra minimum yağıș miktarlarının da araştırılması bu çalışmanın ayırt edici özelliklerindendir.

Çalışmanın izleyen bölümlerinde sırasıyla, kullanılan metodlar tanıtılmış, sonrasında uygulama çalışmasına yer verilmiş ve bulgular, Tartışma ve Sonuç bölümünde açıklanmıştır.

\section{Materyal ve Metot}

Ekstrem Değer Teorisi, temellerini Fisher-Tippett [2], Gnedenko [3] ve Gumbel [4] çalışmalarından alan sıra istatistiğine dayalı bir istatistiksel yaklaşımdır. Rassal değişkenlerin modellenmesi sürecinde Merkezi Limit Teoremi'nin oynadığı rolü, rassal değişkenlerin ekstrem değerleri modellendiği zaman yerini Ekstrem Değer Teorisi'ne bırakır [16]. Her iki teori de, limit dağılımlarının nasıl olması gerektiği üzerinde durur.

Araștırma konusuna uygun olarak ekstrem değerleri elde etmek için sı kullanılan iki yöntem bulunmaktadır. $\mathrm{Bu}$ yöntemlerden uygulamada kullanılan, alt örneklem grupları üzerinden çalışan BM yöntemine izleyen bölümde yer verilmiștir.

\subsection{Blok maksimum yöntemi}

BM yöntemi ile araştırma konusuna uygun olarak belirlenen alt örneklemlere ait ekstrem değerler elde edilir ve işlemlere bu değerler üzerinden devam edilir.

BM yöntemi ile elde edilen ekstrem değerlerin limit dağılımı Fisher ve Tippett [2] teoremi ile açıklanır.

Teorem (Fisher-Tippett): Veri seti $\mathrm{n}$ birimlik alt örneklemlere ayrılsın. Bu alt örneklemlerden elde edilen ekstrem değerler $M_{n}$ ile gösterilsin. $\mathrm{Bu}$ durumda $X_{n}, F$ dağılımı ile bağımsız aynı dağılmış, rassal değişkenlerin bir dizisidir ve $M_{n}=$ $\max \left(X_{1}, X_{2}, \ldots, X_{n}\right)$ olsun.

$$
\frac{M_{n}-d_{n}}{c_{n}} \stackrel{d}{\rightarrow} H
$$

olacak şekilde $c_{n}>0, d_{n} \in I \mathcal{R}$ sabitleri ve $H$ dejenere olmayan dağılım fonksiyonu varsa bu durumda $H$ aşağıdaki üç ekstrem dağılımdan birine aittir. Bu üç ekstrem dağılımın birikimli dağılım fonksiyonları sırasıyla Frechet, Weibull ve Gumbel $[1,9,10]$ olmak üzere aşağıdaki gibidir:

$$
\begin{aligned}
& \mathrm{F}_{\alpha}(x)=\left\{\begin{array}{l}
0, x \leq 0 \\
e^{-x^{-\alpha}}, x>0
\end{array}, \alpha>0\right. \\
& \mathrm{W}_{\alpha}(x)=\left\{\begin{array}{ll}
e^{-(x)^{\alpha}}, & x \leq 0 \\
1, & x>0
\end{array}, \alpha<0\right. \\
& \mathrm{G}(x)=e^{-e^{-x}}, x \in I \mathcal{R}
\end{aligned}
$$

$\mathrm{Bu}$ üç ekstrem dağılım birbiri cinsinden rahatlıkla ifade edilebilmektedir. Birbiri cinsinden yazılabilmeleri bu üç ekstrem dağılımın bir dağılım ailesi olarak değerlendirilmesine neden olmaktadır. $X \sim F_{\alpha}$ dağılımına sahip olduğunda $\ln X^{\alpha} \sim G$ dağılımına 
uyarken $1 / X \sim W_{\alpha}$ dağılıma uyar. Jenkinson-von Mises gösteriminden yola çıkarak Genelleştirilmiş Ekstrem Dağılımını ortaya atmışlardır [2]. Bu dağılım bahsedilen üç ekstrem dağılımın genel bir gösterimi olarak da düşünülebilir. Bu dağılıma ait birikimli dağılım fonksiyonu;

$$
E_{z}(x)=\left\{\begin{array}{rl}
e^{-(1+z x)^{-1 / z}}, & z \neq 0 \\
e^{-e^{-x}}, & z=0
\end{array}, 1+z x>0\right.
$$

Genelleştirilmiş Ekstrem Dağılımının diğer dağllımlara dönüşümü ise şu şekildedir;

- $\quad z=\alpha^{-1}$ alınırsa $E_{z}(x) \sim F_{\alpha}$ dağılımına $\left(\alpha^{-1}>\right.$ 0)

- $z=-\alpha^{-1} \quad$ olarak alınırsa $E_{z}(x) \sim W_{\alpha}$ dağılımına $\left(-\alpha^{-1}<0\right)$

- $\quad z=0$ olarak alınırsa $E_{z}(x) \sim G$ dağılımına

dönüştürülmüş olur.

$\mathrm{Bu}$ dağılımda $z$ değişkeni şekil parametresidir ve dağılımın kuyruk davranışını belirler. Ayrıca $\alpha=1 / z$ kuyruk indeksi olarak da bilinir. Kuyruk davranışlarına göre dağılımlar şu şekilde sinıflandırılabilir;

- Eğer birikimli dağılım fonksiyonu $F$ üstel olarak azalıyorsa $E_{z} \sim \Lambda$, Gumbel dağılımına uyar ve $z=0$, șekil parametresi sıfırdır. Gumbel dağılımı tipindeki dağılımlar, Normal, Log-normal, Üstel ve Gamma dağılımları gibi ince kuyruklu dağılımlardır.

- Eğer birikimli dağılım fonksiyonunun kuyruğu bir kuvvet fonksiyonuna göre azalıyorsa, $E_{z} \sim F_{\alpha}$, Frechet dağllımına uyar ve $z>0$ şekil parametresi sıfırdan büyüktür. Frechet dağılımı benzeri dağılımlar, Pareto, Cauchy ve Student-t dağılımları gibi kalın kuyruklu dağılımlardır.

- Birikimli dağılım fonksiyonunun kuyruğu sonlu ise $E_{z} \sim W_{\alpha}$, Weibull dağılımına uyar ve şekil parametresi $z<0$, sıfırdan küçüktür. Weibull dağılımına benzer dağılımlar Düzgün ve Beta dağılımı tipindeki dağılımlardır [15].

\section{Bulgular (Eskişehir ve İstanbul Bölgelerine ait Yıllık Maksimum ve Minimum Yağış Miktarları Analizi)}

Çalışmanın bu bölümünde 1960-2015 yılları arasında Eskişehir ve 1965-2015 arasında İstanbul-Kartal bölgesinde meydana gelen aylık toplam yağış miktarları (mm) ele alınmıştır. Blok maksimum yöntemi kullanılarak her yıl meydana gelen en yüksek (maksimum) ve en düşük (minimum) yağış miktarları belirlenerek en uygun ekstrem değerler ailesi dağılımları ile modellenmiştir. Tablo 1'de blok maksimum yöntemi ile elde edilen maksimum ve minimum yağış miktarlarından oluşan veriye ilişkin betimleyici istatistikler verilmiştir.

Tablo 1'de görüldüğü gibi İstanbul-Kartal bölgesi Eskişehir bölgesine göre ortalama olarak daha fazla yağış almaktadır.

Tablo 1. Eskişehir ve İstanbul-Kartal bölgeleri için betimleyici istatistikler

\begin{tabular}{lrrrr}
\hline & $\begin{array}{r}\text { Esk. } \\
\text { Maks. }\end{array}$ & $\begin{array}{r}\text { Esk. } \\
\text { Min. }\end{array}$ & $\begin{array}{r}\text { İst. } \\
\text { Maks. }\end{array}$ & $\begin{array}{r}\text { İst. } \\
\text { Min. }\end{array}$ \\
\hline N & 52 & 52 & 47 & 47 \\
Min & 44.90 & 0 & 80.30 & 0 \\
1. Kantil & 64.40 & 0.55 & 107.40 & 0.55 \\
Medyan & 78.20 & 1.80 & 132 & 2.90 \\
Ortalama & 80.18 & 3.07 & 135.40 & 4.12 \\
3. Kantil & 92.22 & 4.30 & 154.50 & 6.70 \\
Maks. & 129.70 & 11.70 & 222.90 & 20.60 \\
\hline
\end{tabular}

Bölgelerin maksimum ve minimum yağıș miktarları $R$ programında yer alan fitdistrplus paketi kullanılarak modellenmiştir [21]. Bu paket kullanıcılara ekstrem değerler ailesindeki dağılımların parametre tahminlerini ve farklı modellerin birbirleri ile karşılaştırılmasında kullanılan Akaike Bilgi Kriteri (AIC) ve Bayes Bilgi Kriteri (BIC) hesaplamasına yardımcı olmaktadır.

Şekil 1'de Eskişehir bölgesinde gerçekleşen maksimum yağış miktarları için Weibull, Gumbel ve Frechet dağılımları birikimli dağılım fonksiyonlarının karşılaştırılması verilmiştir. Görüldüğü gibi Gumbel ve Frechet dağılımları Weibull dağılımına göre veriye daha iyi uyum göstermişlerdir.

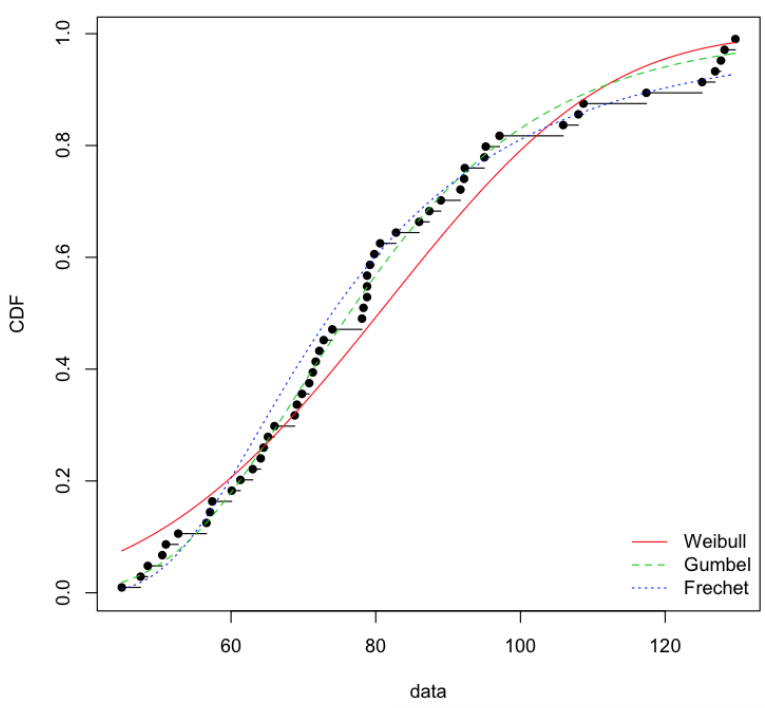

Şekil 1. Eskişehir bölgesi maksimum yağıș miktarları için kümülatif dağılım fonksiyonlarının karşılaștırılması

Şekil 2'de ise yoğunluk fonksiyonlarının karşılaștırılması verilmiştir. Şekil 1'de ki gibi Gumbel ve Frechet dağılımları veriye daha iyi uyum göstermiştir.

Şekil 1 ve 2'de elde edilen bulgular sayısal değerler veren AIC ve BIC kriterleri ile de karşılaştırılmalıdır. 
Tablo 2'de Eskişehir bölgesi maksimum yağış miktarları Weibull, Gumbel ve Frechet dağılımları için model uygunluk kriterleri verilmiştir. Bu kriterler olușturulan modellerin veriye olan uyumsuzluk değerleri olarak yorumlanır. Kriterlerin küçük değerleri ilgili modelin veriye daha uygun olduğunu gösterir. Görülüğü gibi Şekil 1 ve 2'de elde edilen bulgular kriterler ile de desteklenmektedir ve en uygun model Gumbel dağılımıdır.

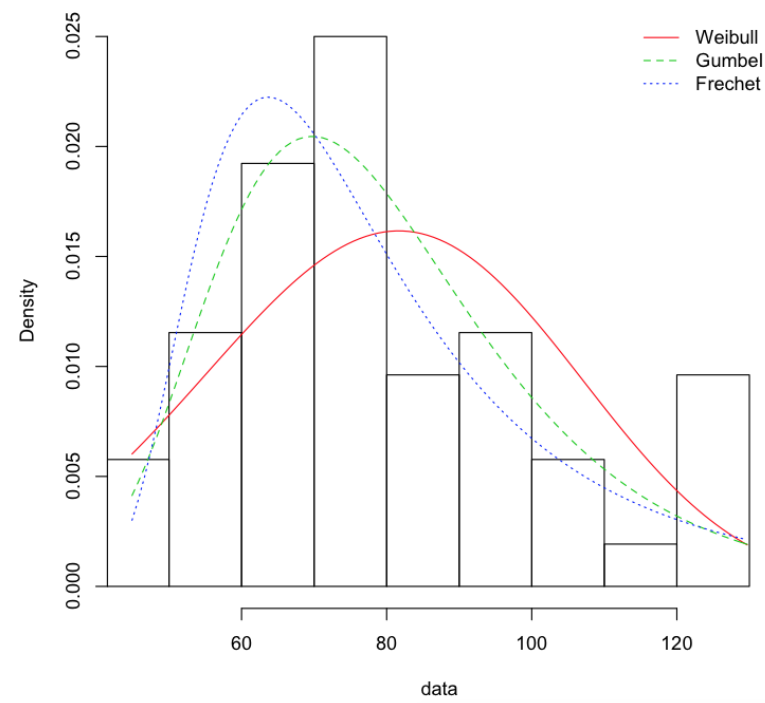

Şekil 2. Eskişehir bölgesi maksimum yağış miktarları için dağılım fonksiyonlarının karşılaștırılması

Tablo 2. Eskişehir bölgesi maksimum yağış miktarları için model uygunluk kriterleri

\begin{tabular}{lcc}
\hline & AIC & BIC \\
\hline Weibull & 476.7821 & 480.6846 \\
Gumbel & 468.9486 & 472.8511 \\
Frechet & 472.6580 & 476.5605 \\
\hline
\end{tabular}

Şekil 3'te ise Eskişehir bölgesi maksimum yağış miktarları için Weibull, Gumbel ve Frechet kümülatif dağılım fonksiyonlarının karş̧laştırılması verilmiştir. Görüldüğü gibi Gumbel dağılımı diğer dağılımlara göre veriye daha iyi uyum göstermişlerdir. Eskişehir bölgesi maksimum yağış miktarları için Gumbel dağılımı parametre tahminleri Tablo 3' te verilmiştir.

Tablo 3. Eskişehir bölgesi maksimum yağış miktarları için Gumbel dağllımı parametre tahminleri

\begin{tabular}{lll}
\hline & Tahmin değeri & Standart hata \\
\hline Şekil & 69.732 & 0.385 \\
Ölçek & 17.991 & 3.484 \\
\hline
\end{tabular}

Şekil 4'te Eskişehir bölgesi minimum yağış miktarları için Weibull, Gumbel ve Frechet yoğunluk fonksiyonlarının karşılaştırılması verilmiştir. Şekil 1'de ki gibi Gumbel ve Frechet dağılımları veriye daha iyi uyum göstermiștir. Tablo 4'te verilen uyum iyiliği kriterlerine göre en uygun dağılım Weibull dağılımıdır.

Eskişehir bölgesi minimum yağış miktarları için Weibull dağılımı parametre tahminleri Tablo 3' te verilmiştir.

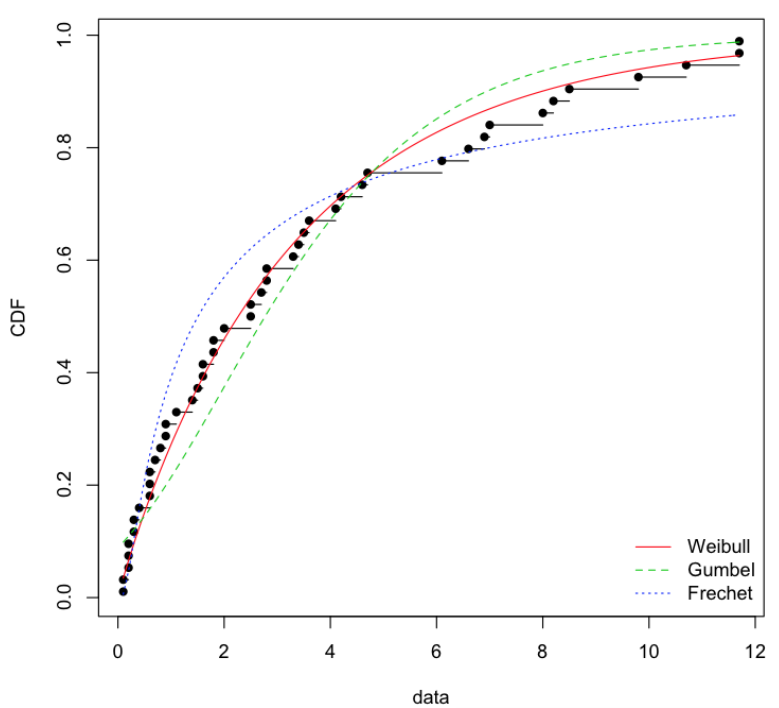

Şekil 3. Eskișehir bölgesi minimum yağıș miktarları için kümülatif dağılım fonksiyonlarının karşılaștırılması

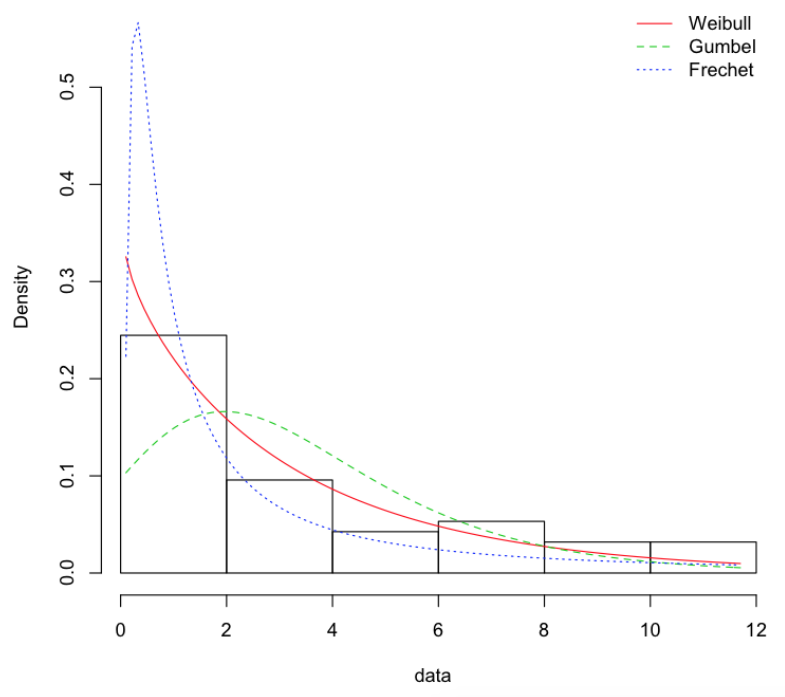

Şekil 4. Eskișehir bölgesi minimum yağıș miktarları için dağılım fonksiyonlarının karşılaştırılması

Tablo 4. Eskişehir bölgesi minimum yağıș miktarları için model uygunluk kriterleri

\begin{tabular}{lcc}
\hline & AIC & BIC \\
\hline Weibull & 212.7494 & 216.4497 \\
Gumbel & 233.6865 & 237.3868 \\
Frechet & 229.1160 & 232.8163 \\
\hline
\end{tabular}

Tablo 5. Eskişehir bölgesi minimum yağıș miktarları için Weibull dağılımı parametre tahminleri

\begin{tabular}{lll}
\hline & Tahmin değeri & Standart hata \\
\hline Şekil & 0.953 & 0.111 \\
Ölçek & 3.325 & 0.536 \\
\hline
\end{tabular}

Şekil 5 ve 6'da İstanbul-Kartal bölgesi maksimum yağıș miktarları için sırasıyla kümülatif dağılım ve dağılım fonksiyonlarının karşılaştırılması verilmiştir. Gumbel dağılımı Tablo 6' da verilen kriter değerlerine göre de en uygun dağılımdır. İstanbul-Kartal bölgesi maksimum yağış miktarları için Gumbel dağılımı parametre tahminleri Tablo 7' de verilmiştir. 


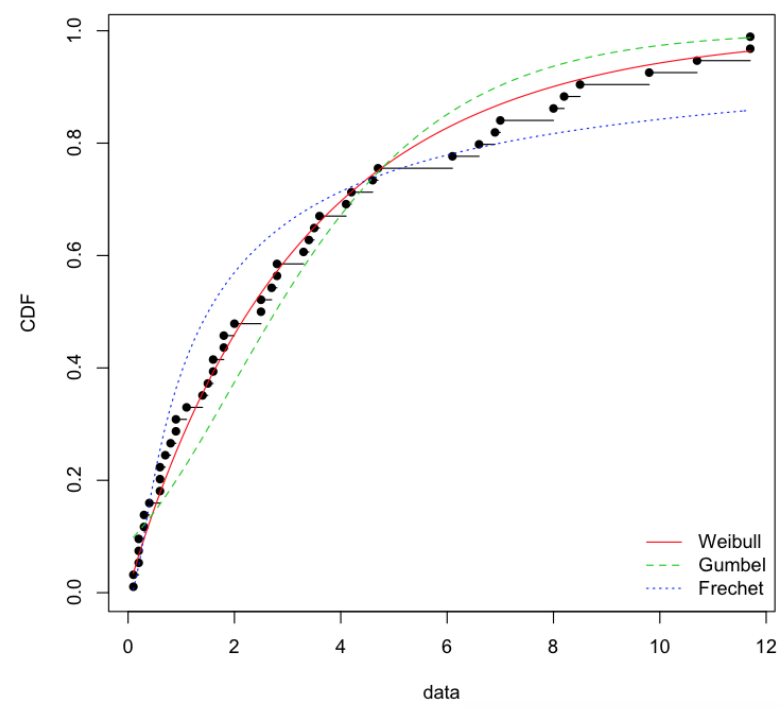

Şekil 5. İstanbul-Kartal bölgesi maksimum yağıș miktarları için kümülatif dağılım fonksiyonlarının karşılaștırılması

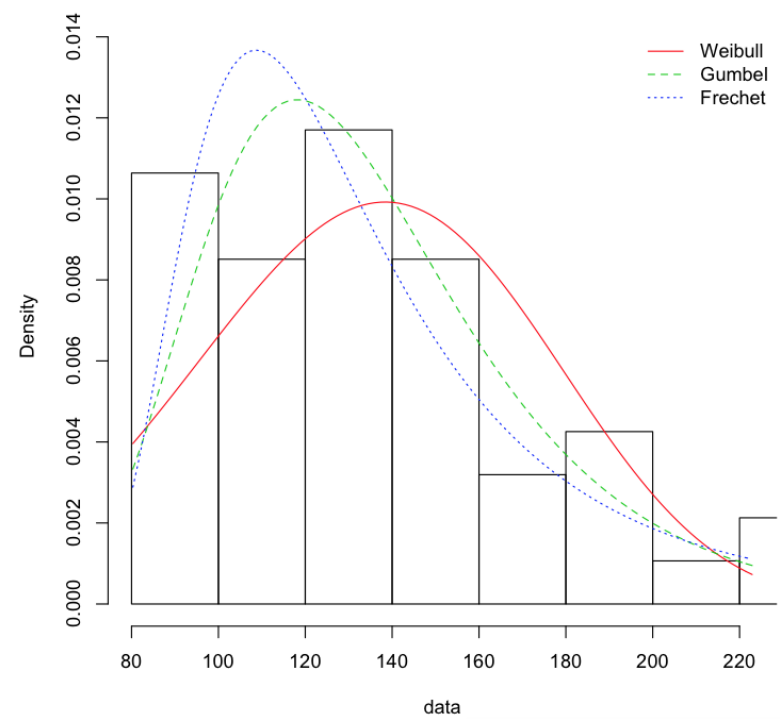

Şekil 6. İstanbul-Kartal bölgesi maksimum yağış miktarları için dağılım fonksiyonlarının karşılaştırılması

Tablo 6. İstanbul-Kartal bölgesi maksimum yağış miktarları için model uygunluk kriterleri

\begin{tabular}{lcc}
\hline & AIC & BIC \\
\hline Weibull & 477.5685 & 481.2688 \\
Gumbel & 471.0467 & 474.7470 \\
Frechet & 473.4729 & 477.1732 \\
\hline
\end{tabular}

Tablo 7. İstanbul-Kartal bölgesi maximum yağıș miktarları için Gumbel dağılımı parametre tahminleri

\begin{tabular}{lll} 
& Tahmin değeri & Standart hata \\
\hline Şekil & 118.126 & 4.526 \\
Ölçek & 29.442 & 3.404 \\
\hline
\end{tabular}

Şekil 7 ve 8'de ise İstanbul-Kartal bölgesi minimum yağış miktarları için sırasıyla kümülatif dağılım ve dağılım fonksiyonlarının karşılaştırılması verilmiştir. Weibull dağılımı Tablo 8' de verilen kriter değerlerine göre de en uygun dağılımdır. İstanbulKartal bölgesi minimum yağış miktarları için Weibull dağılımı parametre tahminleri Tablo 9' da verilmiştir.

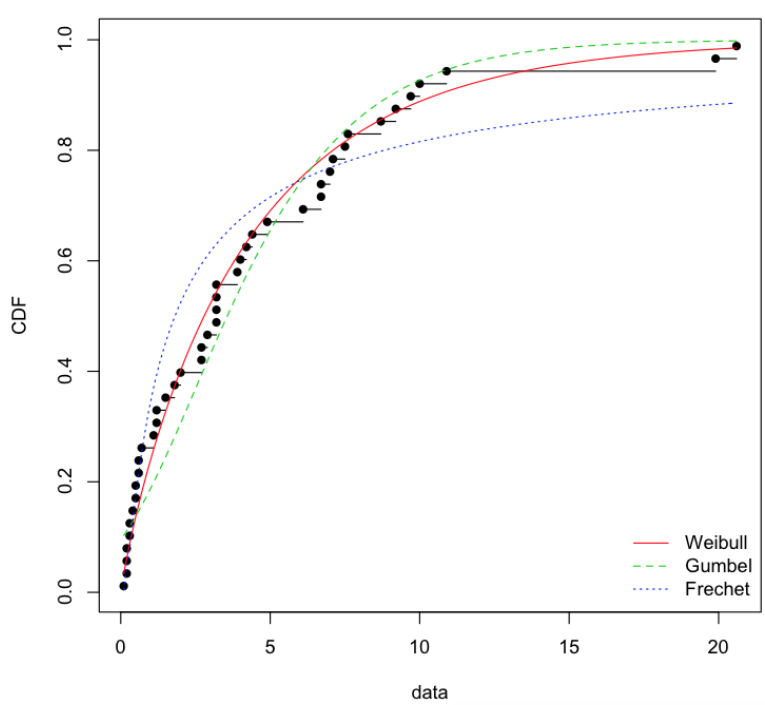

Şekil 7. İstanbul-Kartal bölgesi minimum yağıș miktarları için kümülatif dağılım fonksiyonlarının karşılaştırılması

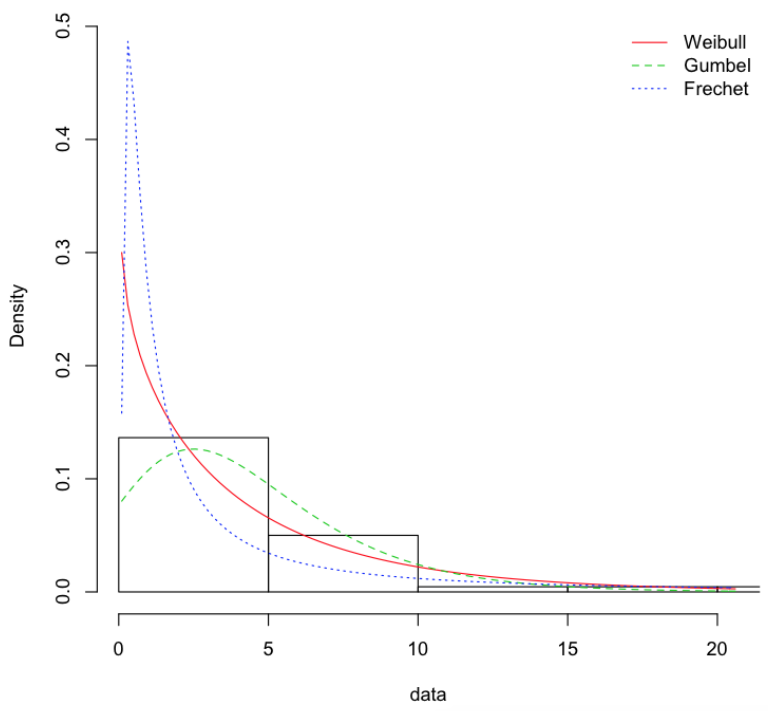

Şekil 8. İstanbul-Kartal bölgesi minimum yağış miktarları için dağılım fonksiyonlarının karşılaştırılması

Tablo 8. İstanbul-Kartal bölgesi minimum yağış miktarları için model uygunluk kriterleri

\begin{tabular}{lcc} 
& AIC & BIC \\
\hline Weibull & 221.5973 & 225.1657 \\
Gumbel & 243.6320 & 247.2004 \\
Frechet & 235.6067 & 239.1751 \\
\hline
\end{tabular}

Tablo 9. İstanbul-Kartal bölgesi minimum yağış miktarları için Weibull dağılımı parametre tahminleri

\begin{tabular}{lll}
\hline & Tahmin değeri & Standart hata \\
\hline Şekil & 0.901 & 0.107 \\
Ölçek & 4.188 & 0.738 \\
\hline
\end{tabular}

\section{Tartışma ve Sonuç}

Grafiklerden de açıkça görüldüğü gibi Eskişehir ve İstanbul-Kartal bölgeleri için elde edilen maksimum ve minimum yağış miktarlarının dağılımları farklılık göstermektedir. İstanbul bölgesinin, Eskișehir bölgesine göre daha fazla yağış aldığı maksimum ve 
minimum yağış

dağılımlarından

gözlemlenebilmektedir.

Çalışmada Ekstrem değerler teorisine uygun olarak ele alınan bölgelerin maksimum ve minimum yağış miktarı verilerine Weibull, Gumbel ve Frechet dağılımları arasından en iyi modelleyen dağılım $\mathrm{R}$ yazılımında yer alan fitdistrplus paketi kullanılarak araştırılmıștır.

Hangi dağllımların maksimum ve minimum verilerine uygun olduğunun belirlenmesi için kümülatif dağılım fonksiyonları ve dağılım fonksiyonları karşılaştırılmasının yanı sıra Akaike ve Bayes Bilgi kriterleri hesaplanmıştır. Böylelikle görsel araçların yanı sıra uyum iyiliği ölçüleri de kullanılmıştır. Uygun dağılım belirlendikten sonra dağılımın parametre tahminleri ve tahminlere ilişkin standart hatalar verilmiştir.

Eskișehir bölgesi maksimum ve minimum yağıș miktarlarının modellenmesi için uygun dağılımın Weibull dağılımı olduğu belirlenmiştir.

İstanbul-Kartal bölgesi maksimum yağış miktarlarının modellenmesi için uygun dağılımın Gumbel dağılımı olduğu belirlenmiştir. İstanbul bölgesi minimum yağış miktarlarının modellenmesi için, Eskişehir bölgesiyle uyumlu olarak Weibull dağılımının en uygun dağllım olduğunu göstermiștir.

Ekstrem (maksimum ve minimum) yağış miktarları nadiren ortaya çıkmakla birlikte, ortaya çıktıklarında ağır ekonomik ve çevresel sorunlara yol açmaktadır. $\mathrm{Bu}$ çalışmada bu tür olayların hangi sıklıkla ortaya çıktıkları uygun dağılımlar belirlenerek ortaya konmuştur. Bu çalışmayı literatürde konu ile ilgili yapılan çalışmalardan ayıran özelliği Eskişehir ve İstanbul-Kartal bölgelerinin ekstrem yağış miktarlarını, Ekstrem Değerler Ailesi dağılımları ile modelleyen ilk çalışma olmasıdır.

Sonuç olarak, Eskişehir ve İstanbul-Kartal bölgelerinin minimum yağıș miktarları için Weibull, maksimum yağış miktarları için Gumbel dağılımının daha iyi uyum sağladığı belirlenmiştir.

\section{Teşekkür}

$\mathrm{Bu}$ çalışma Anadolu Üniversitesi tarafından 1502F066 nolu Bilimsel Araştırma projesi ile desteklenmiştir.

\section{Kaynaklar}

[1] Frechet, M. R. 1927. Sur la loi de probabilit de l'ecart maximum, Ann. Soc. Polon. Math. (Cracovie), 6, 93-116.

[2] Fisher, R. A., Tippett, L. H. C. 1928. Limiting forms of the frequency distribution of the largest or smallest member of a sample. Proceeding of Cambridge Philosophical Society, (1928).

[3] Gnedenko, B. 1943. Sur La Distribution Limite $\mathrm{Du}$ Terme Maximum D'Une Serie Aleatoire. Annals of Mathematics. Second Series, Vol. 44, No. 3(1943), 423-453.

[4] Gumbel, E. 1958. Statistics of Extremes. Colombia University Press. New York.

[5] Davison, A. C. and Smith, R. L. 1990. Models for Exceedances over High Thresholds, Journal of the Royal Statistical Society. Series B (Methodological), 52, (3), pp. 393-442.

[6] Miroslava, U. 1992. The extreme value distribution of rainfall data at Belgrade, Atmosfera, 5, pp.47-56.

[7] S.G. Coles, J.A. Tawn (1996), Modeling extremes of the areal rainfall process J. Roy. Stat. Soc., Ser. B, 58, pp. 329-347.

[8] McNeil A. J. 1999. Extreme Value Theory for Risk Managers, in Internal Modelling and CAD II, 93113.

[9] Embrechts, P. 1998. Modelling Extremal Events for Insurance and Finance. Springer. Newyork.

[10] Weibull, W. 1939. A Statistical Theory of The Strength of Material. Proc. Royal Swedish Institute Engineering Research151:1.

[11] Gumbel, E. J. 1941. "The return period of flood flows": Annals of Mathematical Statistics v. 12, no. $2,163-190$.

[12] Stephens, M. 1977. Goodness-of-fit for the Extreme Value Distribution, Technical Report for the U.S. Army Research Office.

[13] Sukhatme, S. 1972. Fredholm Determinant of a Positive Definite Kernel of a Special Type and Its Application, Ann. Math. Statist., Volume 43, Number 6 (1972), 1914-1926.

[14] Durbin, J. 1973. Weak Convergence of the Sample Distribution Function when Parameters are Estimated. Ann. Statist. 1, no. 2, 279-290.

[15] Stephens, M. 1976. Asymptotic Results for Goodness-of-Fit Statistics with Unknown Parameters. Ann. Statist. 4, no. 2, 357-369.

[16] Gençay, R., Selçuk F. 2004. Extreme value theory and Value-at-Risk:Relative performance in emerging markets. International Journal of Forecasting.

[17] Gilli, M., Kellezi, E. 2006. An Application of Extreme Value Theory for Measuring Risk, Computational Economics, pp.207-228.

[18] Goncu A., Akgul A.K., Imamoğlu O., Tiryakioğlu M. 2012. An analysis of the Extreme Returns Distribution: The Case of the Istanbul Stock 
Exchange, Applied Financial Economics, vol 22, 723-732.

[19] Ferreira, A.,Hann, L.D. 2015. On the Block Maxima Method in Extreme Value Theory: PWM Estimators, The Annals of Statistics, vol.43, pp.276-298.
[20] J. R. M. Hosking, J. R. Wallis and E. F. Wood. 1985. Technometrics Vol. 27, No. 3 (Aug., 1985), pp. 251-261.

[21] Marie Laure Delignette-Muller, Christophe Dutang. 2015. fitdistrplus: An R Package for Fitting Distributions. Journal of Statistical Software, 64(4), 1-34. 